\title{
Use of a Graphic Organiser as a Pedagogical Instrument for the Sustainable Development of EFL Learners' English Reading Comprehension
}

\author{
Wenjuan Qi ${ }^{1,2, \dagger}$ and Yuhong Jiang ${ }^{1, *,+}$ \\ 1 Foreign Languages College, Shanghai Normal University, Shanghai 200234, China; Qijanice@163.com or \\ 1000458540@smail.shnu.edu.cn \\ 2 English Teaching and Research Group, Sanya Huandao Experimental Middle School, Sanya 572019, China \\ * Correspondence: swnu2004@163.com or yhcam@shnu.edu.cn \\ + Contributed equally.
}

check for

updates

Citation: Qi, W.; Jiang, Y. Use of a Graphic Organiser as a Pedagogical Instrument for the Sustainable Development of EFL Learners' English Reading Comprehension. Sustainability 2021, 13, 13748. https:// doi.org/10.3390/su132413748

Academic Editors: Lawrence Jun Zhang and Vincent T. Greenier

Received: 28 September 2021

Accepted: 17 November 2021

Published: 13 December 2021

Publisher's Note: MDPI stays neutral with regard to jurisdictional claims in published maps and institutional affiliations.

Copyright: (c) 2021 by the authors. Licensee MDPI, Basel, Switzerland. This article is an open access article distributed under the terms and conditions of the Creative Commons Attribution (CC BY) license (https:/ / creativecommons.org/licenses/by/ $4.0 /)$.

\begin{abstract}
As a visual teaching tool, a Graphic Organiser aids students by constructing and displaying a graphic of the text's structure, improving students' sustainable development in English reading comprehension. However, few studies have investigated sustainable development in English reading comprehension using Graphic Organisers, although they might play a critical role in this. Thus, by adopting the methods of quasi-experimentation, observation and interview, this paper aims to address the following two questions from the perspectives of Schema Theory and Dual Coding Theory: (1) What is the effect of Graphic Organisers implemented in English reading on English as a foreign language (EFL) learners' sustainable development in English reading comprehension? Is it positive? (2) How do Graphic Organisers affect various groups of EFL learners' sustainable development in English reading comprehension? One hundred students in an EFL school were chosen as research participants for this experiment, and the whole treatment lasted for three months. The results revealed that the application of Graphic Organisers improved EFL learners' sustainable development in English reading comprehension overall. In addition, Graphic Organisers benefited EFL learners with a medium reading ability most in their sustainable development of English reading comprehension; Graphic Organisers also made a certain difference for students with low and high reading abilities.
\end{abstract}

Keywords: Graphic Organisers; visual teaching tool; sustainable development; English reading comprehension

\section{Introduction}

According to the Proposal for Comprehensive Curriculum Reform and Cultivating Morality issued by the Ministry of Education of China in 2014, educators need to focus on students' key competencies - the fundamental competencies for citizens in the 21st century. This refers to a holistic system comprising many dimensions. In the subject of English, there are four specific key competencies, which are as follows: language competence, cultural awareness, thinking quality and learning competence [1]. Since English is a foreign language in our country, English language competence certainly falls under the fundamental part of English education. Concerning language competence, there are five kinds of English language abilities_-listening, speaking, reading, writing and viewing [2]. Reading ability is one of the most crucial factors for learners to cultivate their critical thinking skills, which plays a great role in thinking quality. In addition, from the perspective of cultural awareness, reading materials contain extensive cultural knowledge; to better develop learners' cultural awareness, a deeper understanding of the reading materials seems to be needed for English learners. Furthermore, learning competence can be simultaneously learned from effective reading. Reading is also an essential part of language learning at every 
level. For instance, it can provide a lot of information about language knowledge, such as vocabulary and grammar. In addition, through reading, learners can develop plenty of content knowledge about society, science and nature. Finally, learners can perceive cultural knowledge and cultivate cultural awareness via a huge quantity of reading materials that readers actually use [3].

Ultimately, adequate and efficient English reading contributes to key competencieslanguage competence, cultural awareness, thinking quality and learning competencehighlighted by the subject. While EFL learners shed much light on reading literally, if teachers focus on language knowledge teaching without deep thinking, they will often inevitably conduct shallow learning activities, such as those involving simple memory as well as repetitive and mechanical drills, which pose great limitations for the development of the students' ability to acquire knowledge, construct meaning and solve problems [4]. Meanwhile, many English teachers believe that detailed knowledge of vocabulary, grammar and complex sentences far outweighs the whole structure of reading and logic within the organisation of the text, which naturally gives rise to the learners' underachievement in comprehending the text as a whole.

Comprehending texts by reading and viewing can be a great way to assess and interpret written and visual texts [5]. Reading directs more attention to decoding the literal meaning, whereas viewing aids in perceiving the visual information. Thus, the interactive process of reading and viewing may contribute more to students' reading comprehension. Graphic Organisers represent one of seven comprehension strategies mentioned by the National Reading Panel [6]. This panel reviewed comprehension strategies and endorsed Graphic Organisers applied in English reading classes. Using this strategy, readers make graphic representations of the materials to effectively assist reading comprehension.

Serving as an important tool, Graphic Organisers transform the text structure from mere text to content suitable for discussion during classroom instruction. Graphic Organisers depict the discourse structure by representing the interrelationship among ideas and patterns of the text [7]. Moreover, as a visual teaching tool, a Graphic Organiser could cultivate students' reading comprehension by having them construct and view a graphic of the text structure.

Learner differences play a critical part in English reading comprehension strategies because reading comprehension depends on the relation between a Graphic Organiser and the learner's ability to comprehend the text; however, little research has investigated the influence of individual differences in reading ability on English reading comprehension, when using Graphic Organisers. In addition, there are diverse factors involved in individual differences-for instance, learning style, gender and learning ability. In this thesis, the spotlight was placed on learning ability. As a consequence, this thesis concentrates on the application of Graphic Organisers in English reading teaching for learners of various learning abilities, to investigate an effective way to cultivate learners' reading comprehension.

\section{Literature Review}

\subsection{Graphic Organisers}

Graphic Organisers were previously regarded as advance organisers, which were used to process materials and make outlines of materials more systematic. They were first developed by Barron [8], but similar roots can be found in Ausubel's work [9]. As a way of structuring outlines, Graphic Organisers are regarded as a tool within advance organisers that puts more focus on meaningful learning.

Graphic Organisers are a kind of diagram or graph that represents a relationship directed by a thinking-skill verb. The verb 'sequence' requires a series of block diagrams connected by arrows, which show that the 'event' of one box leads to the 'event' of another box [10]. Graphic Organisers are used to process representations, pictures or models of textual information. When a large amount of information needs to be processed in a given limited time, it can promote the understanding of knowledge [11]. 
When the concept of Graphic Organisers was introduced in China, some researchers gave their unique understanding of it. Given the superficial shape and look, Graphic Organisers refer to knowledge graphs, concept graphs, story graphs, cognitive organisers, advance organisers, concept icons and so on. For example, a Graphic Organiser is a graphical way of elaborating oral and written materials, a visual way of representing information and so on. Graphic Organisers, also called analytical structure diagrams, are a typical representation of a conceptual diagram of visualised thinking. Graphic Organisers can present specific organisational types and structural relationships through specific diagrams, providing teachers and learners with a thinking support framework for using information and cognitive processing [12].

To sum up, Graphic Organisers are a display of vision and graphics, unveiling the relationship between opinions and facts by solving certain learning tasks. Graphic Organisers are used to visually express knowledge, concepts and opinions. They are also pedagogical tools that use visual symbols to express knowledge and concepts through the relationships between them. The prime purpose of Graphic Organisers is to provide visual assistance to facilitate the learning process and give certain guidance for teaching.

\subsection{Application of Graphic Organisers in Teaching Reading}

Some researchers have completed extensive empirical research on Graphic Organisers, and the results show mixed effects for reading with Graphic Organisers on learners' English reading comprehension. Some other studies have shown that Graphic Organisers often positively influence learners' English reading comprehension.

Hawk [13] found significant learning gains after training junior high school students to invent and draw out their unique Graphic Organisers after reading some science texts. In another study, Graphic Organisers constructed by students were found to be more effective than those constructed by teachers [14].

Simmons' [15] study compared teacher-constructed Graphic Organisers before reading with after reading, as well as the more traditional approaches, before, during and after reading. In this study, 11 different Graphic Organisers were used for each chapter in a science textbook. Armbruster, Anderson and Meyer [16] studied how classroom teachers implemented instructional graphics in a university-public school collaboration. Armbruster et al. [16] reported the frame as a 'visual representation of the organisation of important ideas in the informational text'. Three components of the experimental design were as follows: (a) a student framing condition, (b) a teacher-led framing condition and (c) a control condition. Students in Grades 4 and 5 used the frame while reading social studies textbooks for an entire year. At the end of the year they reported that the framing technique was effective for many reasons, such as the development of their thinking ability. Sixty-eight students in Grade 11 from two public schools received a five-week intervention with Graphic Organisers practice, and Graphic Organisers proved to be a beneficial and ample English comprehension strategy [17]. Another study of 26 elementary school students in Grade 4 proved that the implementation of a Graphic Organiser, as part of the teaching materials, can improve reading comprehension skills [18].

A study on the impact of Graphic Organisers on students' learning in a computerbased learning environment compared the effects of successive versus simultaneous presentation of Graphic Organisers. The data indicate that delayed Graphic Organisers can lead students to process the overall information more deeply and improve their learning [19]. Some other experienced teachers have refined a practical way to implement Graphic Organisers in different levels of school, reporting positive results [20-22].

The length of the experiment duration and participants' educational backgrounds are also important factors in the effectiveness of Graphic Organisers [23]. Williams et al. [24] showed that Graphic Organisers support students' acquisition of content via the instruction of organisation patterns in text. Previous studies indicated that Graphic Organisers boost the reading comprehension process by comparing and contrasting informational reading 
materials. Besides, Ozturk [25] also proved that Graphic Organisers can increase learners' English reading comprehension.

Although many studies have found Graphic Organisers beneficial for learning, there have been discrepancies in determining how students learn from Organisers. For instance, some researchers utilising different levels of Graphic Organiser training have found that Graphic Organiser generation by the learner hinders comprehension because of an increased cognitive load [26]. Moreover, Hoffmann [27] found that students' English reading comprehension did not improve after six weeks of experimentation, with Graphic Organisers implemented within contrast text. Previous research has not made clear the groups that can benefit most from Graphic Organisers nor how to choose the corresponding Graphic Organisers for certain reading materials. Minaabad [28] applied dynamic assessment and Graphic Organisers as two teaching methods to support learners' English reading comprehension. The experimental results showed that the dynamic evaluation teaching method gave better results compared with Graphic Organisers.

\section{The Study}

\subsection{Research Questions and Context}

This study aims to answer the two following questions:

1. What is the effect of Graphic Organisers implemented in English reading on EFL learners' sustainable development in English reading comprehension? Is it positive?

2. How do Graphic Organisers affect various EFL learners' sustainable development in English reading comprehension?

The included school was a key school in Zhejiang province, and the participating grade was junior 3. Class 6 was the experimental class, whereas class 5 was the control class. The two classes used the same teaching materials-namely, Junior English Book by People's Education Press [29]. The difference between the two classes was that the experimental class applied Graphic Organisers in their English reading, decoded the text information and paid more attention to the text structure and text organization; the control class adopted the grammar-translation method for training without mentioning Graphic Organisers. The students were selected from the same level, background and reading ability, making the study more convincing.

In terms of the two chosen classes, they were both at an average level among all the classes. One was randomly assigned as the control class and the other as the experimental class. For the control class, 27 male students and 23 female students participated in this study; the mean age of the students was 153 months. In addition, $96 \%$ of the participants (48 students) had attended this same school during the past five years. By contrast, in the experimental class 28 male students and 22 female students participated in this study, and the mean age of the students was 148 months. In addition, $98 \%$ of the participants (49 students) attended this same school during recent years. The basic information of the students in the control group and the experimental group is shown in Table 1, including the details of the participants.

Table 1. Information on the Selected Classes.

\begin{tabular}{ccc}
\hline Groups & Control Class & Experimental Class \\
\hline Class & Class 5 & Class 6 \\
Grade & Junior 3 & Junior 3 \\
Average & 12.75 & 12.3 \\
Number of subjects & 50 & 50 \\
Male & 27 & 28 \\
Female & 23 & 22 \\
Teaching method & Without Graphic Organisers & With Graphic Organisers \\
\hline
\end{tabular}

To ensure the meaningfulness of the result, the two classes needed to have similar levels of English proficiency. According to the score of the first exam, which they did at 
the beginning of this grade, we analysed the average score of each class using SPSS 25.0. This test was chosen because it is a municipal-wide test designed by the Education Bureau. Thus, validity and reliability are guaranteed. Apart from that, this exam is regarded as the pre-test of this experiment. The most essential point is that, according to the results of the SPSS 25.0 analysis of their pre-test, there was no significant difference between the two classes, which proves the homogeneity of the subjects in terms of English proficiency.

As Table 2 shows, the mean of the experimental class before instruction was 79.20, whereas the mean of the control class before instruction was 78.16. Thus, the mean of the experimental class before instruction was slightly higher than the mean of the control class before instruction; thus, we can realise that the overall sustainable development in English reading comprehension of the experimental class was slightly higher than that of the control class.

Table 2. Independent samples $t$-test in the pre-test (1).

\begin{tabular}{cccccc}
\hline & Group & $\boldsymbol{N}$ & Mean & Std. Deviation & Std. Error Mean \\
\hline \multirow{2}{*}{ Grade } & CC & 50 & 78.1600 & 21.30666 & 3.01322 \\
& EC & 50 & 79.2000 & 21.12451 & 2.98746 \\
\hline
\end{tabular}

(CC: control class; EC: experimental class).

Table 3 shows that before instruction, the $F$ value of the experimental class and the control class was $p=0.837>0.05$, indicating that the variance is homogeneous, so we see that the top row $p=0.807>0.05$; thus, there was no significant difference between the experimental class and control class before instruction. In other words, the students from the two classes were appropriate for this experiment.

Table 3. Independent samples $t$-test in the pre-test (2).

\begin{tabular}{|c|c|c|c|c|c|c|c|c|c|}
\hline \multicolumn{5}{|c|}{$\begin{array}{c}\text { Levene's Test for Equality } \\
\text { of Variances }\end{array}$} & \multicolumn{5}{|c|}{$t$-Test for Equality of Means } \\
\hline \multirow{2}{*}{\multicolumn{2}{|c|}{$F$}} & \multirow[t]{2}{*}{ Sig. } & \multirow[t]{2}{*}{$T$} & \multirow[t]{2}{*}{ df } & \multirow[t]{2}{*}{$\begin{array}{c}\text { Sig. } \\
\text { (2-Tailed) }\end{array}$} & \multirow[t]{2}{*}{ MD } & \multirow[t]{2}{*}{$\begin{array}{l}\text { Std. Error } \\
\text { Difference }\end{array}$} & \multicolumn{2}{|c|}{$\begin{array}{l}\text { 95\% Confidence } \\
\text { Interval of the } \\
\text { Difference }\end{array}$} \\
\hline & & & & & & & & Lower & Upper \\
\hline $\begin{array}{l}\text { Equal variances } \\
\text { assumed }\end{array}$ & 0.042 & 0.837 & -0.245 & 98 & 0.807 & -1.04000 & 4.24316 & -9.46041 & 7.38041 \\
\hline $\begin{array}{l}\text { Equal variances not } \\
\text { assumed }\end{array}$ & & & -0.245 & 97.993 & 0.807 & -1.04000 & 4.24316 & -9.46041 & 7.38041 \\
\hline
\end{tabular}

Students in each class were divided into three subgroups based on their scores on the pre-test. To a certain extent, this showed their sustainable development in English reading comprehension ability. They were identified as the reading-high, reading-mid and reading-low groups. The students with scores of 90 and above were identified as the reading-high group; those with scores of 70-89 were identified as the reading-mid group; and those with scores of 69 and under were identified as the reading-low group. Detailed information on the students' distribution is given in Table 4 . 
Table 4. Students' Distribution on Sustainable Development in English Reading Comprehension.

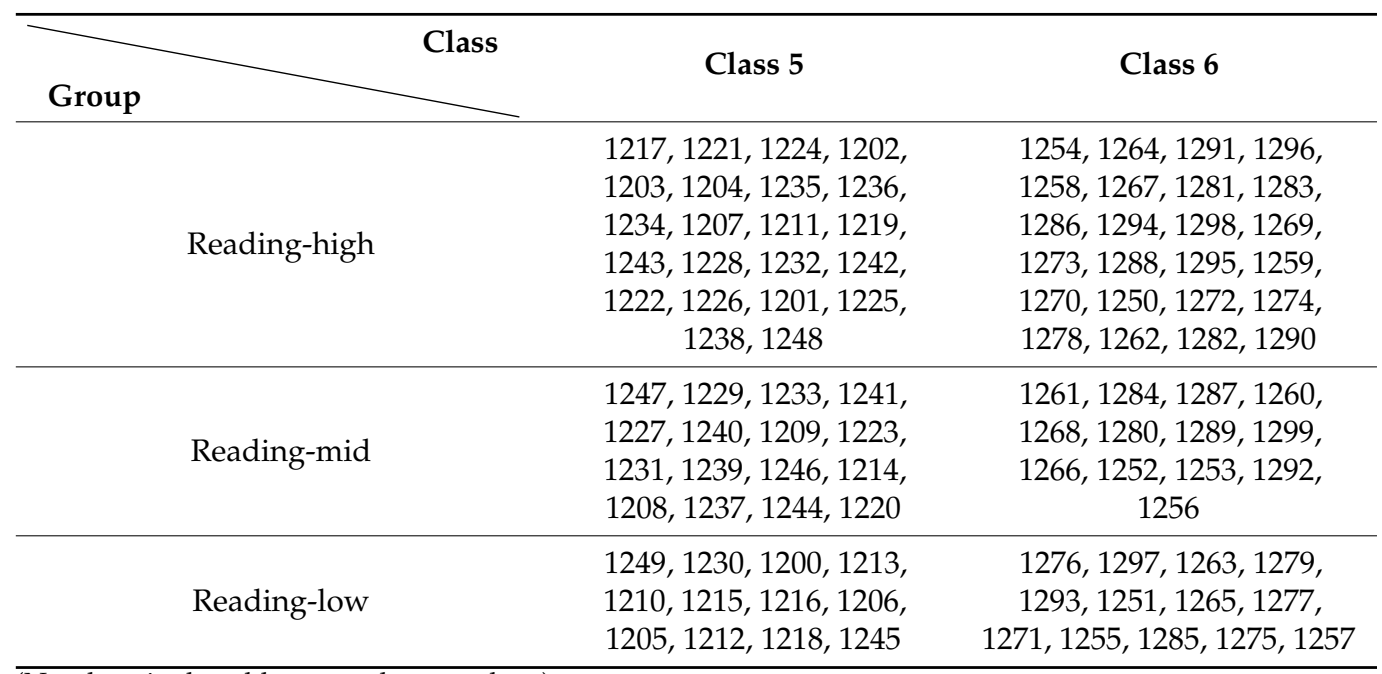

(Numbers in the table are student numbers).

The two classes shared the same English teacher, who had more than 10 years of teaching experience and implemented the whole treatment. To avoid disturbing the normal teaching schedule and considering unnecessary factors, the two classes were as consistent as possible in terms of daily management, teaching schedule and teaching arrangement. To make the experiment as scientific and accurate as possible, the students in both classes were in the most natural state of learning.

\subsection{Research Instruments}

\subsubsection{Pre-Test}

Scores on the learners' sustainable development in English reading comprehension tests before the Graphic Organiser treatment were one of the primary sources of data for this research. They were also used to differentiate students' natural reading proficiency to answer the second research question. The pre-test was taken by 100 students in total, and it included 25 multiple-choice items on four reading passages.

The passages were selected from a municipal-wide English test designed and organised by the Education Bureau. The passages were diverse in topics and with almost the same length and number of test items. The purpose of giving a variety of reading subjects was to avoid topic bias and topic familiarity. Therefore, reliability and validity could be guaranteed. The time allotment for the pre-test was $45 \mathrm{~min}$. In the assessment, the number of points varies according to the item. The 25-point scale was converted into a 100-point scale for a consistent assessment system. Students in the experimental and control classes were all divided into three subgroups (reading-high, reading-mid and reading-low) from the results of the pre-test to determine how Graphic Organisers implemented in English reading affect EFL learners' sustainable development in English reading comprehension for learners with different reading abilities.

\subsubsection{Observation Form}

The experimental class was observed during a three-month instruction period. It was requested that no topics related to knowledge of Graphic Organisers were discussed in the control classes. The lessons in the control class focus on traditional classroom practices, such as vocabulary learning, lexical-grammatical analysis of the text and other classroom activities. In contrast, the experimental class was instructed with the assistance of Graphic Organisers. Therefore, class observation only took place in the experimental group to focus on the fidelity of the instructional treatment and the engagement of different learner groups in English reading when taught with the assistance of Graphic Organisers. 
The focus was directed to the extent to which the teachers appropriately implemented the key elements of the Graphic Organiser lessons, including the amount of time spent on the tasks and the level of student engagement in English reading classroom activities. The observations showed that the class proceeded as planned using the Graphic Organisers instructional approach. To describe and analyse the process of instruction with Graphic Organisers in English reading classes as well as the difference in students' engagement in the English reading class with Graphic Organisers, two quantifiably observational instruments were used. One was applied to observe the whole process of the teacher's treatment, and the other aimed to measure students' degree of engagement in reading instruction involving Graphic Organisers in the classroom, which could indirectly reflect the effect of implementing Graphic Organisers in English reading classes on learners.

From the perspective of teacher observation, a checklist of the steps orchestrating the implementation of Graphic Organisers needed to be observed using a well-designed table. This table included two main parts, which were as follows: (1) basic information about the class, including the teacher's name, number of students, titles of reading materials, whole class time and time used in the activity of Graphic Organisers; and (2) the checklist for the procedure of implementing Graphic Organisers, which comprised three main parts-a preteaching part (e.g., text analysis and the design of Graphic Organisers), a during-teaching part (e.g., introducing Graphic Organisers, co-designing Graphic Organisers and reviewing Graphic Organisers) and a post-teaching part (e.g., improving Graphic Organisers). The observer needed to assign points based on the temporal situation using five-point Likert scales (See Supplementary Materials File S1).

There are many classroom observation instruments that can be used to measure students' degree of engagement in the circumstance of teaching in the classroom. For further study, the researchers conduct student engagement research mainly in terms of the three domains of cognition, emotion and behaviour. Direct classroom observations provide a means of objective measurement of a wide range of behaviours, as they occur in the natural environment. In addition, the use of direct observation allows for the description and evaluation of specific behaviours. This research aims to investigate different learners' reactions to the usage of Graphic Organisers in English reading, so the scale of Behavioural Observation of Students in School (BOSS) put forward by Edward Shapiro has been adopted for the research [30].

BOSS is a systematic observation method based on direct observation of individual students; it is conducted by categorising behaviour at a specific time interval. BOSS is defined as a form of quantitative data collection. Its main purpose is to digitally record what behaviours take place in the observed environment. The measure was developed for use by school psychologists to screen children, especially those at risk of school failure, and for school psychologists, researchers and evaluators to track the effectiveness of interventions over time [31].

Observations in BOSS are coded using the five following categories: Active Engagement, Passive Engagement, Off-Task Motor (OFT-M), Off-Task Verbal (OFT-V) and Off-Task Passive (OFT-P). Actively Engaged Time (AET) is defined as time when the student is actively attending to the assigned work. Passively Engaged Time (PET) is defined as time when the student is passively attending to assigned work. OFT-M is defined as any instance of motor activity that is not directly associated with an assigned academic task. OFT-V is defined as any audible verbalisations that are not allowed or do not relate to an assigned academic task. OFT-P is defined as times when a student is passively not attending to an assigned academic activity for at least 3 s consecutively. Included are those times when a student is quietly waiting after the completion of an assigned task but is not engaged in an activity authorised by the teacher.

The process is best illustrated using an example. When a school counsellor is asked to observe a particular student using BOSS, the researcher aims to make an observation every 15 s over 40 intervals (i.e. a 10 min session). At the end of each $15 \mathrm{~s}$ interval, the counsellor must place the student's behaviour into at least one of the following behaviour categories: 
- $\quad$ AET, such as answering a teacher's question

- PET, such as reading an assigned passage

- OFT-M, such as tapping a pen

- OFT-V, such as talking to a classmate

- OFT-P, such as staring at the door

Next, to be able to compare the target student to the rest of the class, data also needed to be collected for random peers. For this reason, at every fifth interval, the observer directed attention to a random student and classified the student's behaviour during that interval. At the end of $10 \mathrm{~min}$, the observer had 40 data points of behaviour. Thirty-two of the data points reflect the behaviour of the target student, and eight (collected every fifth interval) represented the behaviour of random peers.

Scores from observations are percentages of occurrences of the five categories across the total number of $15 \mathrm{~s}$ intervals observed (percentage of intervals in which the category of engaged/non-engaged behaviours occurred), which can be found in the report of the BOSS application. When reviewing the psychometric properties of the measure, Volpe et al. [32] concluded that reports of inter-observer reliability after training have been consistently high $(90-100 \%)$. Therefore, the reliability and validity of BOSS have been tested, and the instrument is reliable and valid.

\subsubsection{Post-Test}

Results of the post-treatment test were compared with those of the pre-test to evaluate the effectiveness of implementing Graphic Organisers in English reading via the change in students' sustainable development in English reading comprehension performances. The post-test was taken by the 100 students who had completed the pre-test. Results of students from both the experimental and control classes were collected in the post-test.

The post-test was of a parallel construction to the pre-test and used the same sources for its content construction. The reading comprehension passages were still selected from a municipal-wide English test designed and organised by the Education Bureau. The passages were diverse in topics and with almost the same length and number of test items. The purpose of giving a variety of reading subjects was to avoid topic bias and topic familiarity. Therefore, reliability and validity could be guaranteed. The time allotment for the post-test was $45 \mathrm{~min}$. In the assessment, the number of points varies according to the item. The 25-point scale was converted into a 100-point scale for consistent assessment. The same scoring method was adopted as for the pre-test. The time allotment for this test was $45 \mathrm{~min}$, as for the pre-test.

\subsubsection{Interview Protocol}

In this study, the author used structured interviews and individual interviews to carry out the research. Structured interviews have a clear information orientation, and they can elucidate the overall research object with several interviewees and facilitate detailed analysis and comparison of the responses of different respondents. To be more specific, individual interviews only require the interviewer to control the conversation environment, allowing more spontaneous responses to emerge without being directly affected by others [33]. The combination of these two interview methods can provide a deeper understanding of EFL learners' effect on sustainable development in English reading comprehension by implementing Graphic Organisers into English reading.

The two forms of interviews were carried out based on the learners' post-test after instruction; they were conducted as a supplement to the post-test to clarify and better analyse the deep influence of Graphic Organisers. The assortment of a structured interview and an individual interview were developed from three main perspectives, which were as follows: students' attitudes towards Graphic Organisers in English reading, the influence of Graphic Organisers on students and students' expectations of Graphic Organisers. At the same time, each main category included several subcategories (See Supplementary Materials File S2). There was also an extra interview with the teacher from the perspective of pedagogy, 
mainly related to the teacher's feelings about the process of implementing Graphic Organisers and trying to perfect the approach of widely and effectively implementing Graphic Organisers in English reading (See Supplementary Materials File S3).

The student interviewees were randomly chosen from three reading groups (readinghigh, reading-mid, reading-low), and three students from each reading group had a oneon-one natural conversation with the researcher in a quiet location, without any other teachers present. For the teacher interviewee, the researcher had deep conversations with them at the end of the whole experiment to gain a comprehensive understanding of the implementation of Graphic Organisers in English reading.

\subsubsection{Treatment of Graphic Organisers}

The teaching process of implementing Graphic Organisers in English reading classes has been well designed via the cooperation of the researchers and some experienced professors under the guidance of the Proposal for Comprehensive Curriculum Reform and Cultivating Morality and English Curriculum Standards for Compulsory Education.

Formulated based on formal teaching design, the process of implementing Graphic Organisers is embedded into the whole teaching design of an English Reading class, so the teaching design varies as the diverse reading materials change. However, the general rule of how to carry out the application of Graphic Organisers step by step is substantially consistent in every practice. In addition, as Dual Coding Theory and Schema Theory illustrate, the image will impress learners with a unique awareness, such that the Graphic Organisers will help learners in theory.

Generally, the process of implementing Graphic Organisers comprises three main parts-a pre-teaching part, a during-teaching part and a post-teaching part. First, the preteaching part aims to introduce Graphic Organisers and choose the appropriate type for the specific reading text (See Supplementary Materials File S4). Then, the during-teaching part involves filling up the Graphic Organisers by rereading and reanalysing the reading text. This step is a way of cooperating between the learners and the teacher. Ultimately, students will be able to recreate their unique Graphic Organisers according to their understanding independently, in pairs or groups of three. They can both simplify them and elaborate on them, via a combination of the reading text and their imagination.

In this study, the three steps were incorporated into the regular reading curriculum of the experimental classes. Each lesson lasted $45 \mathrm{~min}$. In a typical reading-teaching class with Graphic Organisers, the teacher designed the class ahead of time. The teacher then engaged the class with the process of pre-reading and during-reading activities. Finally, the instructor went over the answers and conducted some post-Graphic Organisers activities, such as reminding students to summarise the main idea of the reading material and answering some text-related comprehension questions. The control class had no access to Graphic Organisers, and the control lessons were taught in such a way that they were not engaged in self-directed activities or participation. Classroom observations confirmed that the instructor of the comparison group did not lecture on Graphic Organisers to aid students' sustainable development in English reading comprehension. Students only conducted the typical pre-reading, during-reading and post-reading activities, as usual.

An example of one reading class teaching design and result is as follows:

Step 1: Pre-teaching

(1) Text analysis:

(What)

This text belongs to the topic context-people's relationship with the self-under the theme of how to be positive in life. It is an interview report that talks about how a 19-year-old Asian pop star, Candy Wang, a really shy girl when she was young, became a famous singer.

(How)

This text can be divided into three parts: the first part mainly talks about the background information of this text and the singer; the middle part covers her features and 
differences between the past and now; and the last part is the singer's suggestions to young people about how to become famous.

(Why)

This text aims to clarify the difficulty of success by sharing the famous singer's story and motivating students to work hard to they can attain success in the future.

(2) Graphic Organiser design:

According to the text analysis and based on the guidance of C. Lewis [34], the Graphic Organiser for this text is given in Figure 1.

(3) Teaching objectives: By the end of this lesson, students will be able to:

(A) Know and use some useful words and phrases for the topic (dare, private, background, interview, Asia, Asian, guard) and acquire the ability to use 'used to' to express a state or action in the past;

(B) Exercise the skill of retelling the whole reading text in general, based on Graphic Organisers finished by the teacher and the class in the passage after reading;

(C) Experience the challenges of success by sharing the famous singer's story and developing motivation to work hard for their success in the future.

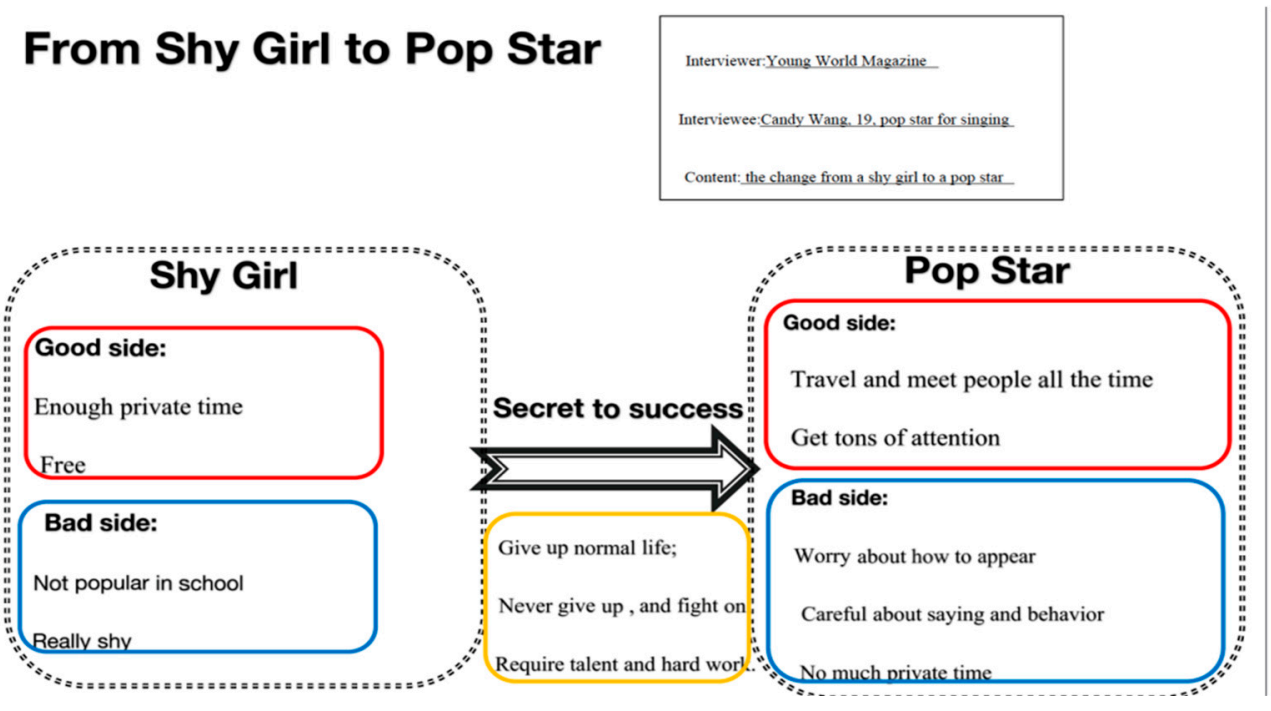

Figure 1. From Shy Girl to Pop Star.

(4) Teaching focus:

(A) Master the new words and phrases in this part to achieve the goal of proficiency and learn to use 'used to' to express a state or action in the past;

(B) Exercise the skill of retelling the whole reading text in general, based on Graphic Organisers finished by the teacher and the class in the passage after reading.

(5) Possible learning difficulties:

Exercise the skill of retelling the whole reading text in general, based on Graphic

Organisers finished by the teacher and the class in the passage after reading.

Step 2: During-teaching

(1) Warming up:

Students will guess that the subject is Candy Wang from her photos and then answer the following questions:

- Who's the pretty girl? She's the famous singer Candy Wang. 
- Could you describe what kind of person she was as a child?

Yeah, she used to be very shy.

- Have you ever heard about her story? Do you want to know more about her?

(2) Fast reading:

Students need to read the passage quickly in a limited time and find out the main ideas of each paragraph. Number the information [1-3].

- _ _ how Candy's life has changed

- __ Candy's advice to young people

- _ Candy's background

(3) Careful reading:

(A) Students will read the first paragraph and answer the following questions:

- How old is Candy?

- What kind of person did she used to be?

- Why did she want to be a singer?

- Did she change a lot? What is she like now?

Next, they need to check their answers with their partners.

(B) Later, students will read the whole passage paragraph by paragraph and complete Graphic Organisers together under the guidance of the teacher.

(4) Post-reading:

Suppose you are an interviewer and your partner will be your interviewee, 'Candy'. You need to ask her some questions, and then she should answer them with the assistance of Graphic Organisers.

Give students an example:

e.g., You: What were you like when you were younger? Are you a born singer?

Your partner: No. I used to be very shy. I began to be interested in singing to overcome my shyness. With more and more practice, I dared to sing in front of my class and then in front of the whole school.

Students work in pairs. Roleplay to ask and answer questions related to the reading material.

Some pairs will be invited to the front to give a performance.

Step 3: Post-teaching

(1) Homework: refine the Graphic Organisers for this text.

(2) Reflection: list the pros and cons of the whole process of teaching.

\subsection{Research Procedure}

In this study, two similar classes (one chosen as a control group, the other as an experimental group) completed a pre-test selected and reorganised from a municipal-wide English test designed by the Education Bureau. As a result, they were categorised into three groups according to their reading ability. The pre-test was taken by 100 students in total. It included twenty-five multiple-choice items for four reading passages.

The teacher was familiarised with the process of instructing students on how to apply Graphic Organisers into English reading teaching to create a realistic situation in the experimental class. Based on Schema Theory, Dual Coding Theory and the rule of applying Graphic Organisers to English reading, the corresponding Graphic Organisers were well designed for each specific teaching material before each class through the cooperation of experienced teachers.

During the three-month experiment, the researcher randomly chose three lessons at the beginning, middle and end, targeting at observing the degree to which the teachers properly implemented the key elements of the Graphic Organiser lessons, including the amount of time spent on the tasks and the level of student engagement in English reading 
classroom activities for the reading-high, reading-mid and reading-low groups in the experimental class.

Involving two quantifiable observational instruments, the class observation only took place in the experimental class and focused on the fidelity of the instructional treatment as well as the engagement of different learner groups in English reading, when taught with the assistance of Graphic Organisers. The observation of the engagement of different learner groups in English reading classes only took place when the teacher was teaching about how to fill in the specific Graphic Organisers and retelling the whole passage with the help of the Graphic Organisers.

The process lasted for around $10 \mathrm{~min}$ at the end of class. The period was video recorded by a camera, and three clips were obtained from the three chosen. The observer watched each clip three times to focus on the reading-high, reading-mid and reading-low students, separately.

After the three-month experiment, the two classes were tested again to check whether teaching with the assistance of Graphic Organisers in English reading affects EFL learners' sustainable development in English reading comprehension and to reveal how Graphic Organisers implemented in English reading affect EFL learners' sustainable development in English reading comprehension for learners with different reading abilities. Finally, additional interviews were carried out to interview the teacher and students from the reading-high, reading-mid and reading-low groups. Nine interviewees (three for each group) were randomly chosen from the three reading groups (reading-high, reading-mid, reading-low) in the experimental class for further study.

\section{Results}

\subsection{Results of the Pre-and Post-Tests}

After the implementation of Graphic Organisers in English reading, the results of the two classes were collected and analysed. From the comparison of the whole control class and experimental class, the results of the descriptive analysis presented how the participants performed on the pre-test and the post-test, as well as the dispersion of the scores on the two tests.

For the control group, the mean scores of the pre- and post-test were $M=78.16(n=50$, $S D=21.31)$ and $M=75.76(n=50, S D=21.01)$, respectively. The small difference between the two mean scores and the standard deviation indicated that the whole control group performed relatively homogeneously (see Table 5).

Table 5. Paired samples $t$-test of the control group.

\begin{tabular}{cccccc}
\hline & n & Minimum & Maximum & Mean & Std. Deviation \\
\hline Pre-test CC & 50 & 20.00 & 98.00 & 78.1600 & 21.30666 \\
Post-test CC & 50 & 19.00 & 97.00 & 75.7600 & 21.01366 \\
\hline
\end{tabular}

For the experimental group, the mean scores of the pre-test and the post-test were $M=79.20(n=50, S D=21.12)$ and $M=83.88(n=50, S D=17.75)$, respectively. There was an obvious difference between the two mean scores and the standard deviation, indicating that the whole experimental group did not perform homogeneously. We can, provisionally, credit this difference to the contribution of Graphic Organisers (see Table 6).

Table 6. Paired samples $t$-test of the experimental group.

\begin{tabular}{cccccc}
\hline & $\mathbf{n}$ & Minimum & Maximum & Mean & Std. Deviation \\
\hline Pre-test EC & 50 & 20.00 & 96.00 & 79.2000 & 21.12451 \\
Post-test EC & 50 & 42.00 & 100.00 & 83.8800 & 17.74725 \\
\hline
\end{tabular}


To further explore whether students' sustainable development in English reading comprehension improved, the data between the pre-test and post-test of the control class and the experimental class were analysed by the paired samples $t$-test using SPSS 25.0.

Judging from the mean in Table 7 , the mean of the control class before the instruction was 78.16, whereas that after the instruction was 75.76. Meanwhile, the mean of the experimental class before the instruction was 79.20, and after the instruction, it was 83.88. Consequently, the means of the experimental class before and after the treatment were greater than the means of the control class, from which we can see that the overall level of the experimental class was slightly higher than that of the control class.

Table 7. Paired samples $t$-test of the control and experimental groups (1).

\begin{tabular}{cccccc}
\hline \multirow{2}{*}{ Pair 1 } & Mean & N & Std. Deviation & Std. Error Mean \\
\cline { 2 - 6 } & Pre-test CC & 78.1600 & 50 & 21.30666 & 3.01322 \\
\hline \multirow{2}{*}{ Pair 2 } & Post-test CC & 75.7600 & 50 & 21.01366 & 2.97178 \\
\cline { 2 - 6 } & Pre-test EC & 79.2000 & 50 & 21.12451 & 2.98746 \\
\hline
\end{tabular}

It can also be seen from Table 8 that before and after the instruction, the control class' $p$-value $=0.000<0.05$, so there was a significant correlation between prior to and after the instruction for the control class. Similarly, before and after the instruction, the experimental class' $p$-value $=0.000<0.05$, so there was also a significant correlation between before and after the instruction for the experimental class. Therefore, both classes were suitable for the paired samples $t$-test.

Table 8. Paired samples $t$-test of the control and experimental groups (2).

\begin{tabular}{ccccc}
\hline & & Mean & N & Std. Deviation \\
\hline Pair 1 & Pre-test CC and Post-test CC & 50 & 0.968 & 0.000 \\
\hline Pair 2 & Pre-test EC and Post-test EC & 50 & 0.970 & 0.000 \\
\hline
\end{tabular}

Table 9 shows that the mean of the test before and after the control class was 2.40 $(t=3.15, p=0.003<0.05)$, so it can be concluded that the post-test results were not as good as the pre-test results. However, there was a significant difference, indicating that under the influence of time and other factors, students' English comprehension was slightly affected. The mean of the test before and after the experiment for the experimental class was -4.68 $(t=-5.708, p=0.000<0.05)$, so it can be inferred that the post-test results are better than the pre-test results, and there are significant differences between them. This indicates that the intervention measures were positive and effective. In other words, no matter what factors improved EFL learners' sustainable development in English reading comprehension, whether it was the influence of time or the positive effect of Graphic Organisers on English reading comprehension, the result is of great significance, and further proof is needed.

Table 9. Paired samples $t$-test of the control and experimental groups (3).

\begin{tabular}{|c|c|c|c|c|c|c|c|c|c|}
\hline & & \multirow{2}{*}{ Mean } & \multirow{2}{*}{$\begin{array}{c}\text { Std. } \\
\text { Deviation }\end{array}$} & \multirow{2}{*}{$\begin{array}{l}\text { Std. Error } \\
\text { Mean }\end{array}$} & \multicolumn{2}{|c|}{$\begin{array}{c}95 \% \text { Confidence Interval } \\
\text { of the Difference }\end{array}$} & \multirow[t]{2}{*}{$t$} & \multirow{2}{*}{$\mathrm{df}$} & \multirow{2}{*}{$\begin{array}{l}\text { Sig. } \\
\text { (2-Tailed) }\end{array}$} \\
\hline & & & & & Lower & Upper & & & \\
\hline Pair 1 & $\begin{array}{l}\text { Pre-test CC } \\
\text { Post-test CC }\end{array}$ & 2.40 & 5.38706 & 0.76185 & 0.86901 & 3.93099 & 3.150 & 49 & 0.003 \\
\hline Pair 2 & $\begin{array}{l}\text { Pre-test EC } \\
\text { Post-test EC }\end{array}$ & -4.68 & 5.79740 & 0.81988 & -6.32760 & -3.03240 & -5.708 & 49 & 0.000 \\
\hline
\end{tabular}


Since it has been shown that the experimental class made progress, it is necessary to determine whether this occurred because of the Graphic Organisers. According to the independent samples $t$-test results for the pre-test, there was no difference between the control class and the experimental class. Therefore, it is necessary to check whether there was a significant difference between the control class and the experimental class after the instruction. If so, this suggests that that there was a positive effect of Graphic Organisers implemented in English reading on EFL learners' sustainable development in English reading comprehension. Otherwise, there was no effect or a negative effect.

The data in the independent samples $t$-test for the post-test of the control class and the experimental class show comparisons between the pre-test and the post-test mean scores for the entire group. The purpose of this comparison is to find out whether the participants made changes in their sustainable development in English reading comprehension performance after the intervention. From the results in Table 10, the mean of the experimental class after the instruction is 83.88 , whereas the mean of the control class after the instruction was 75.76. Thus, the mean of the experimental class after the instruction was much bigger than the mean of the control class after the instruction. It is clear that after the instruction, the overall sustainable development in English reading comprehension of the experimental class was much higher than that of the control class.

Table 10. Independent samples $t$-test in the post-test (1).

\begin{tabular}{cccccc}
\hline & Group & N & Mean & Std. Deviation & Std. Error Mean \\
\hline \multirow{2}{*}{ Grade } & CC & 50 & 75.7600 & 21.01366 & 2.97178 \\
& EC & 50 & 83.8800 & 17.74725 & 2.50984 \\
\hline
\end{tabular}

Table 11 shows that after instruction, the $F$ value of the experimental class and the control class was $p=0.482>0.05$, indicating that the variance is homogeneous, and we see that the top row $p=0.042<0.05$; thus, there was a significant difference between the experimental class and the control class after instruction. In other words, the instruction of Graphic Organisers made a difference in students' sustainable development in English reading comprehension. Specifically, the application of Graphic Organisers in English reading improved EFL learners' sustainable development in English reading comprehension overall.

Table 11. Independent samples $t$-test in the post-test (2).

\begin{tabular}{|c|c|c|c|c|c|c|c|c|c|c|}
\hline & & \multicolumn{2}{|c|}{$\begin{array}{c}\text { Levene's Test for } \\
\text { Equality of } \\
\text { Variances }\end{array}$} & \multicolumn{7}{|c|}{$t$-Test for Equality of Means } \\
\hline & & \multirow[t]{2}{*}{$\mathbf{F}$} & \multirow[t]{2}{*}{ Sig. } & \multirow[t]{2}{*}{$t$} & \multirow[t]{2}{*}{ df } & \multirow[t]{2}{*}{$\begin{array}{l}\text { Sig. (2- } \\
\text { Tailed) }\end{array}$} & \multirow[t]{2}{*}{ MD } & \multirow[t]{2}{*}{$\begin{array}{l}\text { Std. Error } \\
\text { Difference }\end{array}$} & \multicolumn{2}{|c|}{$\begin{array}{l}\text { 95\% Confidence } \\
\text { Interval of the } \\
\text { Difference }\end{array}$} \\
\hline & & & & & & & & & Lower & Upper \\
\hline \multirow{2}{*}{ Grade } & $\begin{array}{c}\text { Equal } \\
\text { variances } \\
\text { assumed }\end{array}$ & 0.482 & 0.489 & -2.060 & 98 & 0.042 & -7.8900 & 3.83045 & -15.49141 & -0.28859 \\
\hline & $\begin{array}{c}\text { Equal } \\
\text { variances } \\
\text { not assumed }\end{array}$ & & & -2.060 & 96.093 & 0.042 & -7.8900 & 3.83045 & -15.49330 & -0.28670 \\
\hline
\end{tabular}

Since the application of Graphic Organisers in English reading has been supported to improve EFL learners' sustainable development in English reading comprehension overall, what needs to be addressed now is how Graphic Organisers implemented in English reading affect EFL learners' sustainable development in English reading comprehension 
for learners with different reading abilities. As previously mentioned, the criterion for classifying participants into different reading groups was based on their performance on the pre-test. Therefore, there were three subgroups in each class-reading-high, readingmid and reading-low. The students with scores of 90 and above made up the reading-high group; those with scores of 70 and above made up the reading-mid group; and those with scores under 70 made up the reading-low group. The purpose of grouping the participants according to their reading ability was to investigate the post-test performance of the originally different reading groups after training on GOs. The aim was to determine whether learners of different reading groups performed differently on the post-test, after being taught with the assistance of Graphic Organisers.

The results of the paired samples $t$-test in Table 12 show that the mean of the readinghigh group was 93.54 before the instruction and 94.50 after the instruction. Meanwhile, the mean of the reading-mid group was 83.69 before the instruction and 92.08 after the instruction. For the reading-low group, the mean was 48.23 before the instruction and 56.08 after the instruction. Therefore, the means of the reading-high, reading-mid and reading-low groups were higher after the intervention than before, so we can see that all three groups indeed improved after being taught English reading with the assistance of Graphic Organisers.

Table 12. Paired samples $t$-test of the three groups (1).

\begin{tabular}{cccccc}
\hline & & Mean & N & Std. Deviation & Std. Error Mean \\
\hline \multirow{2}{*}{ Pair 1 } & Reading-high (Pre) & 93.5417 & 24 & 2.12601 & 0.43397 \\
\cline { 2 - 6 } & Reading-high (Post) & 94.5000 & 24 & 2.57074 & 0.52475 \\
\hline \multirow{2}{*}{ Pair 2 } & Reading-mid (Pre) & 83.6923 & 13 & 5.31326 & 1.47363 \\
\cline { 2 - 6 } & Reading-mid (Post) & 92.0769 & 13 & 3.86138 & 1.07095 \\
\hline \multirow{2}{*}{ Pair 3 } & Reading-low (Pre) & 48.2308 & 13 & 17.69253 & 4.90703 \\
\cline { 2 - 6 } & Reading-low (Post) & 56.0769 & 13 & 11.07897 & 3.07275 \\
\hline
\end{tabular}

Table 13 shows the difference of the results prior to and after the instruction, and the reading-high group's $p$-value $=0.000<0.05$; thus, there exists a significant difference prior to and after the instruction for the reading-high group. Similarly, before and after the instruction, the reading-mid group's $p$-value $=0.006<0.05$, so there is also a significant difference prior to and after the instruction for the reading-mid group. Furthermore, for the reading-low group, $p=0.000<0.05$ prior to and after the instruction. Consequently, all the three groups are related, which means they are suitable for the paired samples $t$-test.

Table 13. Paired samples $t$-test of the three groups (2).

\begin{tabular}{lllcc}
\hline & & N & Correlation & Sig. \\
\hline Pair 1 & Reading-high (Pre and Post) & 24 & 0.807 & 0.000 \\
Pair 2 & Reading-mid (Pre and Post) & 13 & 0.716 & 0.006 \\
Pair 3 & Reading-low (Pre and Post) & 13 & 0.944 & 0.000 \\
\hline
\end{tabular}

Table 14 illustrates that the mean of the test before and after the instruction for the reading-high group was $-0.958(t=-3.094, p=0.005<0.05)$; it can be concluded that the post-test results were better than the pre-test results, and there was a significant difference. This indicates that with the assistance of Graphic Organisers, students' English comprehension improved slightly. The mean of the test before and after the instruction for the reading-mid group was $-8.385(t=-8.151, p=0.000<0.05)$, and the mean of the test before and after the instruction for the reading-low group was $-7.846(t=-3.492$, $p=0.004<0.05$ ); thus, it can be inferred that the post-test results were better than the 
pre-test results, and the differences were significant. This indicates that the intervention measures were positive and effective for the reading-mid and reading-low groups.

Table 14. Paired samples $t$-test of three groups (3).

\begin{tabular}{|c|c|c|c|c|c|c|c|c|c|}
\hline & & \multirow[t]{2}{*}{ Mean } & \multirow[t]{2}{*}{$\begin{array}{l}\text { Std. Devi- } \\
\text { ation }\end{array}$} & \multirow[t]{2}{*}{$\begin{array}{l}\text { Std. Error } \\
\text { Mean }\end{array}$} & \multicolumn{2}{|c|}{$\begin{array}{l}\text { 95\% Confidence } \\
\text { Interval of the } \\
\text { Difference }\end{array}$} & \multirow[t]{2}{*}{$t$} & \multirow[t]{2}{*}{ df } & \multirow[t]{2}{*}{$\begin{array}{l}\text { Sig. } \\
\text { (2-Tailed) }\end{array}$} \\
\hline & & & & & Lower & Upper & & & \\
\hline Pair 1 & $\begin{array}{l}\text { Reading-high (Pre) } \\
\text { Reading-high (Post) }\end{array}$ & -0.95833 & 1.51741 & 0.30974 & -1.59908 & -0.31759 & -3.094 & 23 & 0.005 \\
\hline Pair 2 & $\begin{array}{l}\text { Reading-mid (Pre) } \\
\text { Reading-mid (Post) }\end{array}$ & -8.38462 & 3.70896 & 1.02868 & -10.62592 & -6.14331 & -8.151 & 12 & 0.000 \\
\hline Pair 3 & $\begin{array}{l}\text { Reading-low (Pre) } \\
\text { Reading-low (Post) }\end{array}$ & -7.84615 & 8.10191 & 2.24707 & -12.74209 & -2.95022 & -3.492 & 12 & 0.004 \\
\hline
\end{tabular}

To conclude, the data in the paired samples $t$-test for the post-test showed statistically significant differences between the pre-test and post-test scores for the reading-high, reading-mid, and reading-low groups. However, the levels of significance varied among the groups.

A one-way analysis of variance (ANOVA) was used to further examine the post-test mean differences between the reading-high, reading-mid and reading-low groups. The results showed statistically significant differences among the three groups for the pre-test $(F=98.874, p=0.000)$ and the post-test $(F=177.560, p=0.000)$ (see Tables 15 and 16). The three reading groups performed significantly differently on the pre-test from one another as well as on the post-test after the GO training.

Table 15. One-way ANOVA of the three groups in the pre-test (1).

\begin{tabular}{|c|c|c|c|c|c|c|c|c|}
\hline & \multirow[t]{2}{*}{$\mathbf{N}$} & \multirow[t]{2}{*}{ Mean } & \multirow{2}{*}{$\begin{array}{c}\text { Std. } \\
\text { Deviation }\end{array}$} & \multirow{2}{*}{$\begin{array}{l}\text { Std. Error } \\
\text { Mean }\end{array}$} & \multicolumn{2}{|c|}{$\begin{array}{c}95 \% \text { Confidence Interval } \\
\text { of the Difference }\end{array}$} & \multirow[t]{2}{*}{ Minimum } & \multirow[t]{2}{*}{ Maximum } \\
\hline & & & & & Lower & Upper & & \\
\hline Reading-high & 24 & 93.5417 & 2.12601 & 0.43397 & 92.6439 & 94.4394 & 90.00 & 96.00 \\
\hline Reading-mid & 13 & 83.6923 & 5.31326 & 1.47363 & 80.4815 & 86.9031 & 73.00 & 89.00 \\
\hline Reading-low & 13 & 48.2308 & 17.69253 & 4.90703 & 37.5393 & 58.9223 & 20.00 & 69.00 \\
\hline Total & 50 & 79.2000 & 21.12451 & 2.98746 & 73.1965 & 85.2035 & 20.00 & 96.00 \\
\hline
\end{tabular}

Table 16. One-way ANOVA of the three groups in the pre-test (2).

\begin{tabular}{cccccc}
\hline & Sum of Squares & df & Mean Square & F & Sig. \\
\hline Between groups & $17,666.965$ & 2 & 8833.482 & 98.874 & 0.000 \\
Within groups & 4199.035 & 47 & 89.341 & & \\
Total & $21,866.000$ & 49 & & & \\
\hline
\end{tabular}

Since there were significant differences in test performance among the groups, an LSD post hoc test was employed to conduct multiple comparisons among the post-test mean scores. On the pre-test, there were statistically significant differences between the reading-low and the reading-high $(p=0.000)$, reading-low and reading-mid $(p=0.000)$ and reading-mid and reading-high groups ( $p=0.004$; see Table 17). On the post-test, however, the post hoc tests revealed no statistically significant difference between the reading-mid and reading-high groups $(p=0.262>0.05)$. This indicated that the statistical gap between the reading-high and the reading-mid groups was narrowed. From another perspective, we can see that the reading-mid group's sustainable development in English reading comprehension improved substantially during the research period with the help 
of Graphic Organisers (see Tables 18-20; see Figures 2 and 3 for the change before and after the instruction).

Table 17. One-way ANOVA of the three groups in the pre-test (3).

\begin{tabular}{|c|c|c|c|c|c|c|}
\hline \multirow[t]{2}{*}{ Groups } & \multirow[t]{2}{*}{ Groups } & \multirow{2}{*}{ Mean Difference } & \multirow{2}{*}{ Std. Error } & \multirow[t]{2}{*}{ Sig. } & \multicolumn{2}{|c|}{$\begin{array}{l}\text { 95\% Confidence Interval of the } \\
\text { Difference }\end{array}$} \\
\hline & & & & & Lower & Upper \\
\hline \multirow{2}{*}{ Reading-high } & Reading-mid & $9.84936^{*}$ & 3.25499 & 0.004 & 3.3012 & 16.3976 \\
\hline & Reading-low & 45.31090 * & 3.25499 & 0.000 & 38.7627 & 51.8591 \\
\hline \multirow{2}{*}{ Reading-mid } & Reading-high & $-9.84936^{*}$ & 3.25499 & 0.004 & -16.3976 & -3.3012 \\
\hline & Reading-low & $35.46154 *$ & 3.70740 & 0.000 & 28.0032 & 42.9199 \\
\hline \multirow{2}{*}{ Reading-low } & Reading-high & -45.31090 * & 3.25499 & 0.000 & -51.8591 & -38.7627 \\
\hline & Reading-mid & $-35.46154 *$ & 3.70740 & 0.000 & -42.9199 & -28.0032 \\
\hline
\end{tabular}

${ }^{*}$ Mean difference is significant at the 0.05 level.

Table 18. One-way ANOVA of the three groups in the post-test (1).

\begin{tabular}{|c|c|c|c|c|c|c|c|c|}
\hline & \multirow[t]{2}{*}{$\mathbf{N}$} & \multirow[t]{2}{*}{ Mean } & \multirow{2}{*}{$\begin{array}{c}\text { Std. } \\
\text { Deviation }\end{array}$} & \multirow{2}{*}{$\begin{array}{l}\text { Std. Error } \\
\text { Mean }\end{array}$} & \multicolumn{2}{|c|}{$\begin{array}{l}95 \% \text { Confidence Interval } \\
\text { of the Difference }\end{array}$} & \multirow[t]{2}{*}{ Minimum } & \multirow[t]{2}{*}{ Maximum } \\
\hline & & & & & Lower & Upper & & \\
\hline Reading-high & 24 & 94.5000 & 2.57074 & 0.52475 & 93.4145 & 95.5855 & 90.00 & 99.00 \\
\hline Reading-mid & 13 & 92.0769 & 3.86138 & 1.07095 & 89.7435 & 94.4103 & 85.00 & 100.00 \\
\hline Reading-low & 13 & 56.0769 & 11.07897 & 3.07275 & 49.3820 & 62.7719 & 42.00 & 70.00 \\
\hline Total & 50 & 83.8800 & 17.74725 & 2.50984 & 78.8363 & 88.9237 & 42.00 & 100.00 \\
\hline
\end{tabular}

Table 19. One-way ANOVA of the three groups in the post-test (2).

\begin{tabular}{cccccc}
\hline & Sum of Squares & df & Mean Square & F & Sig. \\
\hline Between groups & $13,629.434$ & 2 & 6814.717 & 177.560 & 0.000 \\
Within groups & 1803.846 & 47 & 38.380 & & \\
Total & $15,433.280$ & 49 & & & \\
\hline
\end{tabular}

Table 20. One-way ANOVA of the three groups in the post-test (3).

\begin{tabular}{cccccccc}
\hline \multirow{2}{*}{ Groups } & \multirow{2}{*}{ Groups } & Mean Difference & Std. Error & Sig. & \multicolumn{2}{c}{$\begin{array}{c}\text { 95\% Confidence Interval of the } \\
\text { Difference }\end{array}$} \\
\cline { 3 - 8 } & & & & Lower & Upper \\
\hline \multirow{2}{*}{ Reading-high } & Reading-mid & 2.42308 & 2.13341 & 0.262 & -1.8688 & 6.7149 \\
\cline { 2 - 7 } & Reading-low & $38.42308^{*}$ & 2.13341 & 0.000 & 34.1312 & 42.7149 \\
\hline \multirow{2}{*}{ Reading-mid } & Reading-high & -2.42308 & 2.13341 & 0.262 & -6.7149 & 1.8688 \\
\cline { 2 - 8 } & Reading-low & $36.00000^{*}$ & 2.42993 & 0.000 & 31.1116 & 40.8884 \\
\hline \multirow{2}{*}{ Reading-low } & Reading-high & $-38.42308^{*}$ & 2.13341 & 0.000 & -42.7149 & -34.1312 \\
\cline { 2 - 8 } & Reading-mid & $-36.00000^{*}$ & 2.42993 & 0.000 & -40.8884 & -31.1116 \\
\hline
\end{tabular}

* Mean difference is significant at the 0.05 level. 


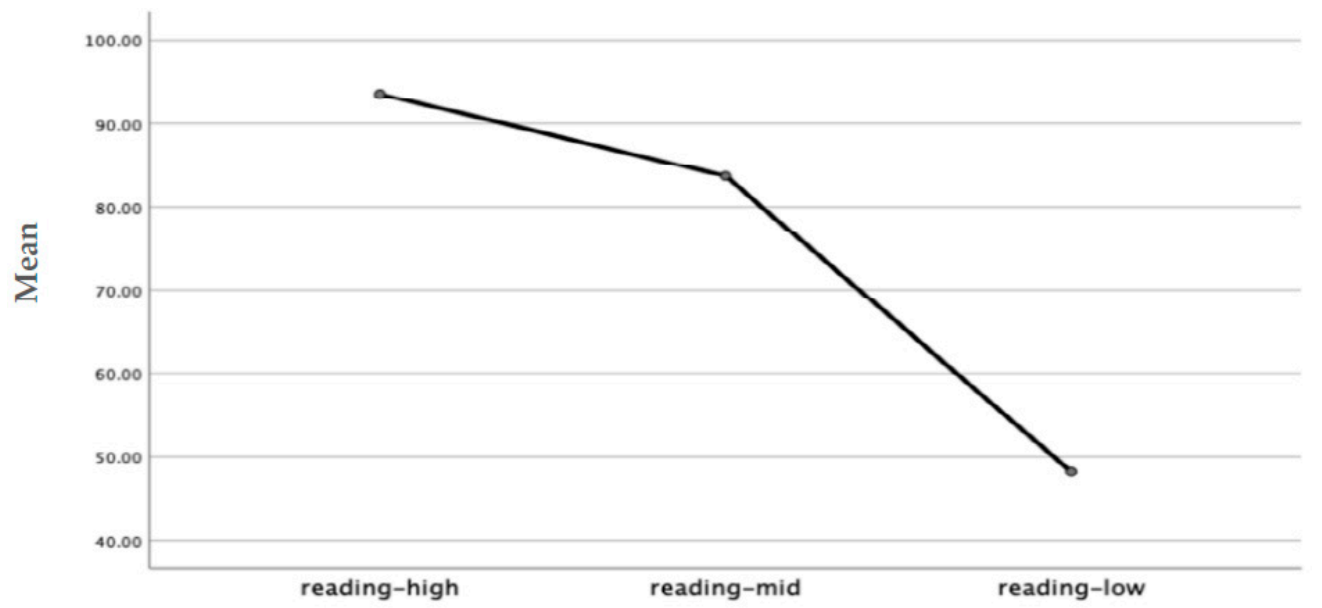

Figure 2. One-way ANOVA of three groups in the pre-test.

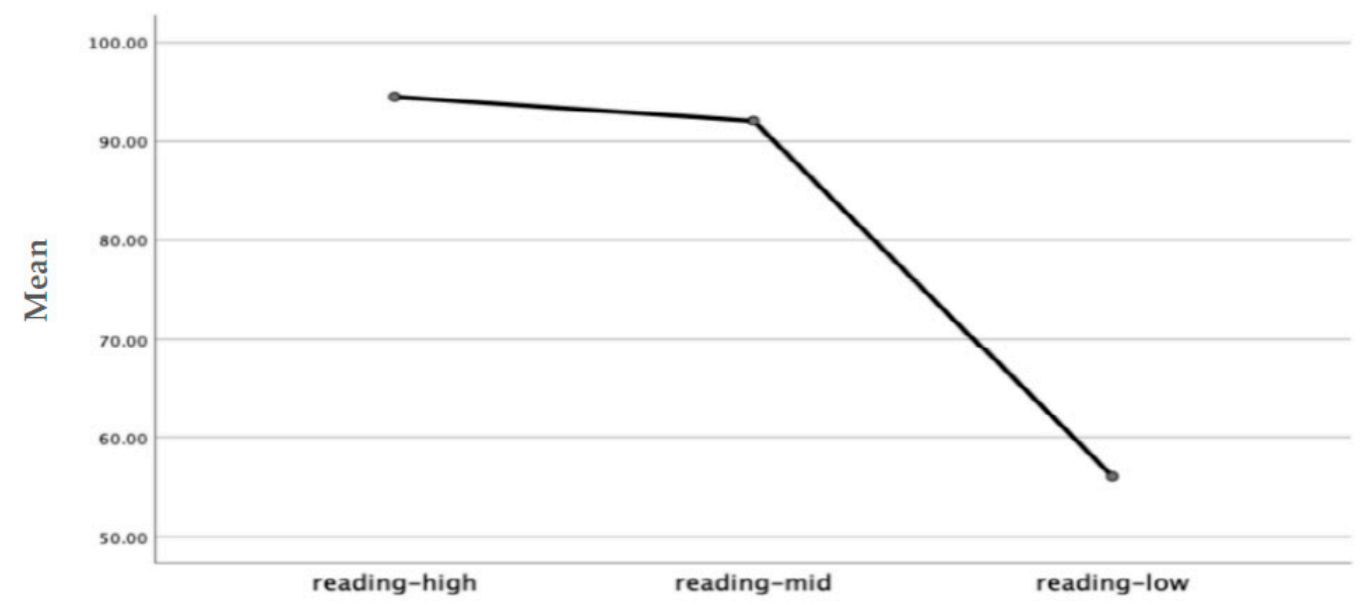

Figure 3. One-way ANOVA of three groups in the post-test.

\subsection{The Results of Observation}

When referring to classroom observation, two facets need to be considered. The first aspect is students' participation in the class while learning the application of specific Graphic Organisers related to the text. The BOSS scale put forward by Shapiro was used to measure the degree of engagement of students with teaching English reading with Graphic Organisers in the classroom, illustrating the learners' tendency to learn English reading with the assistance of Graphic Organisers.

The observation of students' participation was conducted three times and with three groups of participants in the experimental class. The observation was conducted at the beginning of the experiment (Period 1), in the middle period (Period 2) and at the end of the intervention (Period 3). When deciding what kind of action learners' behaviour belonged to, the video clips were observed twice by two raters, and the result was based on the final agreement of the two raters after discussion. The observed subjects were a group of learners with various reading abilities, so the results showed the representative behaviour of the whole group, illustrating that it is normal if there is sometimes no representative behaviour and no result for that interval. Furthermore, if there were two kinds of representative behaviour, the two results were recorded.

Table 21 shows that in the first observation, the statistical frequency of AET for students with low reading ability was 0 , whereas that of PET was 3, accounting for $9 \%$ of the observations. The statistical frequency of OFT-M was 13, accounting for $40 \%$ of the observations; the statistical frequency of OFT-V was 10, accounting for $31 \%$; and the statistical frequency of OFT-P was 9, accounting for $28 \%$. Analysis of the data shows that at 
the beginning of the experiment, English reading with the assistance of Graphic Organisers did not attract students with low reading ability at all. They had a low degree of effective participation in learning, and there was little difference in the frequency and percentage of the three kinds of off-task behaviours-OFT-M, OFT-V and OFT-P.

Table 21. Reading-low (Period 1).

\begin{tabular}{ccccc}
\hline & \multicolumn{2}{c}{ Target Students } & \multicolumn{2}{c}{ Random Peer } \\
\hline & Count & Percentage & Count & Percentage \\
\hline AET & 0 & 0 & 3 & 37 \\
PET & 3 & 9 & 1 & 12 \\
OFT-M & 13 & 40 & 1 & 12 \\
OFT-V & 10 & 31 & 1 & 12 \\
OFT-P & 9 & 28 & 2 & 25 \\
\hline
\end{tabular}

In the second observation, the statistical frequency of AET for students with low reading ability was 1 , accounting for $3 \%$, and that of PET was 14 , accounting for $43 \%$ of the observations. The statistical frequency of OFT-M was 8 , accounting for $25 \%$; the statistical frequency of OFT-V was 7, accounting for $21 \%$; and the statistical frequency of OFT-P was 3 , accounting for $9 \%$. According to the analysis of the data, the statistical frequency of engaged time and time off task for the students with low reading ability was the same. The statistical frequency of PET was much higher than that of AET, whereas the statistical frequencies of OFT-M and OFT-V were fairly small, but both are higher than that of OFT-P. The results are shown in Table 22.

Table 22. Reading-low (Period 2).

\begin{tabular}{ccccc}
\hline & \multicolumn{2}{c}{ Target Students } & \multicolumn{2}{c}{ Random Peer } \\
\hline & Count & Percentage & Count & Percentage \\
\hline AET & 1 & 3 & 3 & 37 \\
PET & 14 & 43 & 3 & 37 \\
OFT-M & 8 & 25 & 1 & 12 \\
OFT-V & 7 & 21 & 0 & 0 \\
OFT-P & 3 & 9 & 3 & 37 \\
\hline
\end{tabular}

For the third observation, Table 23 shows that the statistical frequency of AET for students with low reading ability was 4 , accounting for $12 \%$, and that of PET was 15 , accounting for $46 \%$ of the observations. The statistical frequency of OFT-M was 2, accounting for $6 \%$; the statistical frequency of OFT-V was 8 , accounting for $25 \%$; and the statistical frequency of OFT-P was 2, accounting for $6 \%$. According to the analysis of the data, the statistical frequency of engaged time was higher than that of time off task for the students with low reading ability. The statistical times of PET were much higher than those of AET, whereas the statistical frequency of OFT-M and OFT-P were equal to each other but lower than that of OFT-V.

Table 23. Reading-low (Period 3).

\begin{tabular}{ccccc}
\hline & \multicolumn{2}{c}{ Target Students } & \multicolumn{2}{c}{ Random Peer } \\
\hline & Count & Percentage & Count & Percentage \\
\hline AET & 4 & 12 & 2 & 25 \\
PET & 15 & 46 & 3 & 37 \\
OFT-M & 2 & 6 & 0 & 0 \\
OFT-V & 8 & 25 & 3 & 37 \\
OFT-P & 2 & 6 & 0 & 0 \\
\hline
\end{tabular}


For the observation of the reading-mid group, it can be seen from Table 24 that in Period 1 the statistical frequency of AET for students with middle reading ability was 5, accounting for $15 \%$, and that of PET was 15 , accounting for $46 \%$ of the observations. The statistical frequency of OFT-M was 0 ; the statistical frequency of OFT-V was 8, accounting for $25 \%$; and the statistical frequency of OFT-P was 6 , accounting for $18 \%$. Based on the analysis of the data, the statistical frequency of PET was much higher than that of AET. In addition, the statistical frequency of PET was three times that of AET, while the difference between the statistical frequency of OFT-P and OFT-V was small, and the statistical frequency of OFT was 0 .

Table 24. Reading-mid (Period 1).

\begin{tabular}{ccccc}
\hline & \multicolumn{2}{c}{ Target Students } & \multicolumn{2}{c}{ Random Peer } \\
\hline & Count & Percentage & Count & Percentage \\
\hline AET & 5 & 15 & 2 & 25 \\
PET & 15 & 46 & 2 & 25 \\
OFT-M & 0 & 0 & 0 & 0 \\
OFT-V & 8 & 25 & 2 & 25 \\
OFT-P & 6 & 18 & 1 & 12 \\
\hline
\end{tabular}

For the second observation, it can be seen from Table 25 that the statistical frequency of AET for students with middle reading ability was 5, accounting for $15 \%$, and that of PET was 17 , accounting for $53 \%$ of the observations. The statistical frequency of OFT-M was 1 , accounting for $3 \%$; the statistical frequency of OFT-V was 6 , accounting for $18 \%$; and the statistical frequency of OFT-P was 6 , accounting for $18 \%$. From the analysis of the data, it can be seen that the statistical frequency of engaged time for students with middle reading ability was higher than that of off-task time, where the statistical frequency of PET was 3.4 times that of AET. The statistical frequencies of OFT-P and OFT-V were the same, and they were both much higher than that of OFT-M.

Table 25. Reading-mid (Period 2).

\begin{tabular}{ccccc}
\hline & \multicolumn{2}{c}{ Target Students } & \multicolumn{2}{c}{ Random Peer } \\
\hline & Count & Percentage & Count & Percentage \\
\hline AET & 5 & 15 & 2 & 25 \\
PET & 17 & 53 & 3 & 37 \\
OFT-M & 1 & 3 & 0 & 0 \\
OFT-V & 6 & 18 & 1 & 12 \\
OFT-P & 6 & 18 & 2 & 25 \\
\hline
\end{tabular}

In the third observation for the reading-mid group, it can be seen from Table 26 that the statistical frequency of AET for students with middle reading ability was 11, accounting for $34 \%$, and that of PET was 18, accounting for $56 \%$ of the observations. The statistical frequency of OFT-M was 0 ; the statistical frequency of OFT-V was 1, accounting for 3\%; and the statistical frequency of OFT-P was 2, accounting for $6 \%$. By analysing the data, it can be seen that the statistical frequency of engaged time for students with middle reading ability was far higher than that of time off task, among which the statistical frequency of PET was higher than that of AET. Moreover, the statistical frequencies of OFT-M, OFT-P and OFT-V were all low. 
Table 26. Reading-mid (Period 3).

\begin{tabular}{ccccc}
\hline & \multicolumn{2}{c}{ Target Students } & \multicolumn{2}{c}{ Random Peer } \\
\hline & Count & Percentage & Count & Percentage \\
\hline AET & 11 & 34 & 2 & 25 \\
PET & 18 & 56 & 5 & 62 \\
OFT-M & 0 & 0 & 0 & 0 \\
OFT-V & 1 & 3 & 1 & 12 \\
OFT-P & 2 & 6 & 0 & 0 \\
\hline
\end{tabular}

As for the reading-high group, it can be seen from Table 27 that in Period 1, the statistical frequency of AET for students with high reading ability was 15, accounting for $46 \%$, and that of PET was 16, accounting for $50 \%$ of the observations. The statistical frequency of OFT-M was 0; the statistical frequency of OFT-V was 0; and the statistical frequency of OFT-P was 2, accounting for $6 \%$. According to the analysis of the data, it can be seen that the statistical frequencies of engaged time for students with reading ability were much higher than those of time off task, among which the statistical times of PET and AET were the same, whereas the statistical times of OFT-M, OFT-P and OFT-V were all low.

Table 27. Reading-high (Period 1).

\begin{tabular}{ccccc}
\hline & \multicolumn{2}{c}{ Target Students } & \multicolumn{2}{c}{ Random Peer } \\
\hline & Count & Percentage & Count & Percentage \\
\hline AET & 15 & 46 & 1 & 12 \\
PET & 16 & 50 & 4 & 50 \\
OFT-M & 0 & 0 & 0 & 0 \\
OFT-V & 0 & 0 & 1 & 12 \\
OFT-P & 2 & 6 & 2 & 25 \\
\hline
\end{tabular}

For the second observation, it can be seen from Table 28 that the statistical frequency of AET for students with high reading ability was 24 , accounting for $75 \%$, and that of PET was 8 , accounting for $25 \%$ of the observations. The statistical frequencies of OFT-M, OFT-V and OFT-P were all 0 . According to the analysis of the data, students with high reading ability spent the whole time in engaged time, and the statistical frequency of AET was three times that of PET.

Table 28. Reading-high (Period 2).

\begin{tabular}{ccccc}
\hline & \multicolumn{2}{c}{ Target Students } & \multicolumn{2}{c}{ Random Peer } \\
\hline & Count & Percentage & Count & Percentage \\
\hline AET & 24 & 75 & 4 & 50 \\
PET & 8 & 25 & 4 & 50 \\
OFT-M & 0 & 0 & 0 & 0 \\
OFT-V & 0 & 0 & 0 & 0 \\
OFT-P & 0 & 0 & 0 & 0 \\
\hline
\end{tabular}

For Period 3, it can be seen from Table 29 that the statistical frequency of AET for students with high reading ability was 25 , accounting for $78 \%$, and that of PET was 7 , accounting for $21 \%$ of the observations. The statistical frequencies of OFT-M, OFT-V and OFT-P were all 0 . According to the analysis data, students with high reading ability spent all their time in engaged time, and the statistical frequency of AET was 3.5 times that of PET. 
Table 29. Reading-high (Period 3).

\begin{tabular}{ccccc}
\hline & \multicolumn{2}{c}{ Target Students } & \multicolumn{2}{c}{ Random Peer } \\
\hline & Count & Percentage & Count & Percentage \\
\hline AET & 25 & 78 & 5 & 62 \\
PET & 7 & 21 & 3 & 37 \\
OFT-M & 0 & 0 & 0 & 0 \\
OFT-V & 0 & 0 & 0 & 0 \\
OFT-P & 0 & 0 & 0 & 0 \\
\hline
\end{tabular}

By comparing the three observational datasets of the students with low reading ability, we can state that after using the Graphic Organisers, the number of students in the engaged time increased significantly in Periods 2 and 3 compared with Period 1, but there was still far more PET than AET. Correspondingly, the number of students in off-task time reduced in each observation, and OFT-M and OFT-P decreased greatly.

Through the observation data of students with the middle reading ability, what can be seen is that after using Graphic Organisers, the number of engaged students in Period 3 was increased compared with Period 2, and the number of engaged students in Period 2 increased compared with Period 1. The number of AET students in Period 3 increased significantly compared with Period 1, and the number of PET students in Period 3 was unchanged. The off-task time of students in the reading-mid group was mainly represented by OFT-V and OFT-P, and during Period 3 the statistics showed a significant decrease compared with the previous periods.

The three observational datasets of the students with high reading ability showed that students with high reading ability were almost always engaged. After using the Graphic Organisers, the number of AET students in Period 2 was higher than that in Period 1, and the number of students in AET in Period 3 was nearly the same as that in Period 2. As a result, the number of PET students in Period 3 was almost equal to that in Period 2, and the number of PET students in the three observations was low.

As for the teacher observation, the scores of the evaluations of teachers' implementation of Graphic Organisers in English reading were 20, 26 and 29 in Periods 1, 2 and 3, respectively. For each step in the observation, for the first evaluation, the specific scores were as follows: Step 1: 3 points; Step 2: 3 points; Step 3: 4 points; Step 4: 3 points; Step 5: 4 points; and Step 6: 3 points. In the second evaluation, the specific scores were as follows: Step 1: 4 points; Step 2, 4 points; Step 3: 5 points; Step 4: 4 points; Step 5: 5 points; and Step 6: 4 points. For the third evaluation, the specific scores were as follows: Step 1: 5 points; Step 2: 4 points; Step 3: 5 points; Step 4: 5 points; Step 5: 5 points; and Step 6: 5 points.

According to the analysis and synthesis of all the score data, what is clear is that the teacher became increasingly thorough in the analysis of articles, more rigorous in the design and more able to attract students' attention in the teaching process. All these points can improve students' learning efficiency, enhancing their ability to identify the key points in after-class summary and make rapid improvement.

\section{Discussion}

\subsection{The Overall Effect of Graphic Organisers}

The data analysis found statistical evidence to support the effectiveness of Graphic Organisers as a sustainable development in English reading comprehension for the entire participant group. The overall significant result of Graphic Organisers implemented in English reading for EFL learners may be illustrated by the three-month experimental period. Jiang and Grabe [35] stated that the instructional application of Graphic Organisers for English reading development purposes is a collective process that benefits from long-term, consistent exposure. Bean et al. [36] suggested that Graphic Organiser instruction should take at least a semester, and the students need to be totally and consistently exposed to and 
work with the Graphic Organisers. Nevertheless, short-term Graphic Organisers training may not provide students with sufficient exposure to relate textual discourse to Graphic Organisers. Three months is neither too long nor too short, which is an ideal amount of time for the experiment to represent the effect of Graphic Organisers implemented in English reading on EFL learners' sustainable development in English reading comprehension.

Robinson and Kiewra [37] found that delayed review is necessary for GOs to be effective. However, given the time limit in this study, a follow-up investigation of Graphic Organisers was not possible.Moreover, this research aimed to investigate the immediate effect of Graphic Organisers on sustainable development in English reading comprehension. Thus the follow-up investigation was not part of the design in this case because of the time limit.

To determine the whole effect of the application of Graphic Organisers on EFL learners' reading comprehension in English reading, an independent samples $t$-test was carried out, once before the experiment and once after the experiment. After analysing the collected data, it can be said that in the pre-test there was no difference between the experimental class and the control group; after the instruction, the data in the independent samples $t$-test from the post-test of the control and experimental classes showed a significant difference between the two groups. In other words, the instruction involving Graphic Organisers made a difference in students' sustainable development in English reading comprehension. To be specific, the application of Graphic Organisers in English reading improved EFL learners' sustainable development in English reading comprehension in total, which suggests that the treatment positively affected the sustainable development in English reading comprehension performance of this group.

To further explore whether students' sustainable development in English reading comprehension improved, the data between the pre-test and post-test of the control group and the experimental group were analysed by the way of paired samples $t$-tests using SPSS 25.0. For the experimental class, the post-test results were better than the pre-test results, and the differences were significant, indicating that the intervention measures were positive and effective. Therefore, the positive effects of Graphic Organisers implemented in English reading on EFL learners' sustainable development in English reading comprehension were proved by the data.

\subsection{The Impact of Graphic Organisers on Learners with Diverse Reading Abilities}

Since the positive effects of Graphic Organisers implemented in English reading on reading comprehension have been clarified, the effects of Graphic Organisers on the learning of learners with diverse reading abilities was unveiled after the analysis and synthesis of the data from the pre-test, post-test and BOSS observation. According to the data from the paired samples $t$-test for the post-test, the means of the reading-high, reading-mid and reading-low groups after the instruction were larger than those before the instruction, so we can see that all three groups improved when taught English reading with the assistance of Graphic Organisers. The data in the paired samples $t$-test for the post-test showed statistically significant differences between the pre-test and post-test scores for the reading-high, reading-mid and reading-low groups, but the differences varied from one another.

A one-way ANOVA was used to further examine the post-test mean differences between the reading-high, reading-mid and reading-low groups. Since there were significant differences in test performance among the groups, an LSD post hoc test was employed to conduct multiple comparisons among the post-test mean scores. The results indicated that the statistical gap between the reading-high and reading-mid groups was narrowed. From another perspective, we can see that the sustainable development in English reading comprehension of the reading-mid group improved substantially during the instruction, with the help of Graphic Organisers.

The BOSS observation provided important insight into the level of engagement that students are showing in the classroom. BOSS offers the essential data needed to more 
clearly understand the aspects of the educational environment that may be affecting student performance. BOSS data can also be useful in achieving a fuller understanding of the nature of academic engagement among students who are commonly known to be at risk for academic failure.

For the reading-low group, we can state that after using the Graphic Organisers the number of students in engaged time increased significantly in Periods 2 and 3 compared with Period 1, but there was still far more PET than AET. Correspondingly, the number of students in off-task time decreased in each observation, and OFT-M and OFT-P decreased greatly. Most students with low reading ability did not not like Graphic Organisers because they thought that the logic of Graphic Organisers was too complex to comprehend, and they could not keep up with the teaching speed of the teacher, which affected the learning efficiency of English reading for the whole class. Compared with Graphic Organisers, students are more willing to read and discuss after reading. Graphic Organisers are helpful to recall the reading paragraph and better understand the vocabulary in the passage.

As for the reading-mid group, after using Graphic Organisers the number of students in engaged time in Period 3 increased dramatically compared with Period 2, and a similar increase was found in Period 2 compared with Period 1. Clearly, the number of AET students in Period 3 increased significantly compared with Period 1, and the number of PET students in Period 3 was almost unchanged. The off-task time of students in the reading-mid group was mainly represented by OFT-V and OFT-P, and during Period 3 the statistics showed a significant decrease compared with the previous two periods. They liked to use Graphic Organisers in the reading class because they thought they made reading more targeted and purposeful. Besides, it is a way of making great use of class time, thereby improving their learning efficiency. Compared with discussion activities, Graphic Organisers made students more devoted to reading and helped them memorise the theme and ideas of the material. In addition, students were also more willing to fill in Graphic Organisers after reading activities. They thought that Graphic Organisers could help them understand the whole reading content and main ideas of the text, distinguish the theme and details correctly, locate the central idea to better recall the reading paragraphs and develop ideas and then combine them to form the main idea.

Finally, for the reading-high group, the statistical data of the students with high reading ability almost all related to engaged time. After using the Graphic Organisers, the number of students in AET in Period 2 was higher than that in Period 1, and the number of students in AET in Period 3 was basically the same as that in Period 2. As a result, the number of PET students in the third observation was almost equal to that in the second observation, and the number of PET students in the three observations was low. When referring to using Graphic Organisers, students with high reading ability in the reading class held an indifferent attitude because they thought that Graphic Organisers were much too simple and something of a waste of time. As a result, the effect of Graphic Organisers in terms of improving their reading ability was not obvious. Therefore, there is no difference in learning efficiency between the teaching approach of implementing Graphic Organisers into English reading and other teaching approaches. Apart from that, students still argue that Graphic Organisers play a role in helping them better locate ideas in articles and combine detailed ideas into themes.

\section{Conclusions}

This study found evidence that Graphic Organisers implemented in English reading are effective for EFL learners' sustainable development in English reading comprehension. Specifically, Graphic Organisers were statistically evaluated as an effective and positive way to boost students' sustainable development in English reading comprehension, supporting the finding by Lin that students have positive perceptions of morphological instruction [38]. This finding could also support previous claims concerning the use of visual aids in helping these readers recognise text structures and transfer pure text of words to a visual format. Considering all the findings, what is strongly recommended is that teachers should try 
their best to use Graphic Organisers as an efficient, beneficial and instructional strategy, especially in English reading.

The second result of the study was that the group with middle reading ability performed better than the lower and higher groups in terms of sustainable development in English reading comprehension. This finding is different from previous studies, stating that Graphic Organisers have the most benefit for students with low reading ability. The findings suggested that when implementing Graphic Organisers in English reading instruction, students' reading abilities should probably be considered. The question about how to make reading-low students improve into reading-middle and reading-high students still needs to be explored.

However, there is still some improvement needed to be done.. The insufficient amount of time teaching the awareness of discourse structures and implementing the GO types better representing those structures of the texts was another main reason for underachieving in terms of the Graphic Organisers effectiveness. Furthermore, because of the time limits, students may not have had a sufficient amount of practice or consistent exposure to different types of reading texts in the whole treatment of Graphic Organisers. This may have led to a lack of knowledge and the absence of the delayed review necessary for GO use to be effective.

As for the process of implementing Graphic Organisers in English reading, based on the teacher observation mentioned above, the scores of the three marks that evaluated teachers' implementation of Graphic Organisers in English reading classes were 20, 26 and 29, in Periods 1, 2 and 3, respectively. By analysing the score data, it is clear that the teacher became increasingly thorough in the analysis of the texts, more rigorous in the design and more able to attract the attention of the student in the teaching process. All of those points can help improve students' learning efficiency and make them more able to identify the key points in after-class summary, resulting in rapid improvement.

After the experiment, the teachers shared the experience and understanding about whether the implementation of Graphic Organisers in English reading enhanced students' sustainable development in English reading comprehension. They expressed that it is hard to design suitable Graphic Organisers for certain texts because this requires a group discussion and takes a lot of time. In addition, it is unclear which Graphic Organisers will be suitable for a certain reading passage; this is why they also mentioned that designing a suitable Graphic Organiser is the most difficult part of implementing Graphic Organisers. The barrier when teaching Graphic Organisers in English reading, as expressed, was the ability to design a perfect Graphic Organiser in a short amount of time. However, when asked whether Graphic Organisers were beneficial for EFL learners in terms of their sustainable development in English reading comprehension, the instructor approved of the approach immediately without any hesitation and added that learners with the middle reading ability benefit most from Graphic Organisers. In addition, it is difficult to design suitable Graphic Organisers for a particular text because this requires group discussions and a lot of time. Moreover, the choice of an appropriate Graphic Organiser for a reading article is sometimes ambiguous, and the study unveiled that designing an appropriate Graphic Organiser is the most difficult part of implementing Graphic Organisers. In other words, the obstacle to teaching Graphic Organisers in English reading is to design a perfect Graphic Organiser in a short amount of time.

Given the aforementioned limitations of the research study, it is strongly suggested that future studies of this topic should take into greater consideration the amount of time for the experiment, a better way to test learners' reading ability and a more detailed and effective way to choose and design a perfect Graphic Organiser for a certain reading passage. The number of experiments might need to be greatly increased.

To conclude, the potential of Graphic Organisers for improving EFL learners' sustainable development of English reading comprehension was explored. Fortunately, statistical significance was seen for all groups of students, while students with middle reading ability did improve a lot after Graphic Organisers were implemented in the English reading class. 
However, unfortunately, learners with low reading ability and high reading ability have their own unique characteristics, resulting in the limitation of improvement of English reading comprehension, which may be the key breakthrough for later research to make a huge difference.

Supplementary Materials: The Supplementary Materials for this article are available online at https: / /www.mdpi.com/article/10.3390/su132413748/s1: File S1. Teacher Observation Form; File S2. Student Interview Protocol; File S3. Teacher Interview Protocol; File S4. Graphic Organisers and Text Structures.

Author Contributions: Y.J. conceived of and designed the study. W.Q. collected and analysed the data and wrote the first draft. Y.J. and W.Q. rewrote the subsequent drafts. All the authors revised the manuscript before Y.J. finalised and submitted it as the corresponding author, sharing first authorship. All the authors have made substantial, direct, and intellectual contributions to the work, have contributed equally and share first authorship, and approved it for publication. All authors have read and agreed to the published version of the manuscript.

Funding: The paper is supported by the research project "University English Teachers' Thinking and Practice Routes in the Integration of Ideological Education into Course Teaching in the Context of the 'New Outlines'"' (Grant Number: C2022405), sponsored by Shanghai Municipal Educational Science Planning Project; the research project "A Practical Study of the Instructional Mode of Integrating Reading and Writing Based on the Thematic Reading" (Grant Number: CERA1351210), sponsored by the China English Reading Academy and Foreign Language Teaching and Research Press; the research project "Municipal Key Courses of the Universities in Shanghai-'English Curriculum and Pedagogy"', sponsored by Shanghai Municipal Education Commission; and the project "Exploring the Route and Measures of the Integration of Critical Thinking into English Language Teaching", sponsored by the Shanghai Centre for Research in English Language Education.

Institutional Review Board Statement: The study was conducted according to the guidelines of the Declaration of Helsinki, and approved by the Institutional Review Board (or Ethics Committee) of Shanghai Normal University (July 2020).

Informed Consent Statement: Informed consent was obtained from all subjects involved in the study. Written informed consent has been obtained from the patient(s) to publish this paper.

Data Availability Statement: The original contributions presented in the study are included in the article/Supplementary Materials, further inquiries can be directed to the corresponding author.

Acknowledgments: Many thanks to the administrative and technical support from my supervisor Professor Yuhong Jiang. All the authors appreciate the constructive suggestions from the editor and the anonymous reviewers.

Conflicts of Interest: The authors declare that the research was conducted in the absence of any commercial or financial relationships that could be construed as a potential conflict of interest.

\section{References}

1. Ministry of Education, PRC. English Curriculum Standards for General High School, 2017th ed.; People's Education Press: Beijing, China, 2018.

2. Common Core State Standards Initiative. Common Core State Standards for English Language Arts \& Literacy in History/Social Studies, Science, and Technical Subjects. 2010. Available online: http://www.corestandards.org/assets/CCSSI_ELA\%20 Standards.pdf (accessed on 10 February 2021).

3. Jiang, Y. A Study on Professional Development of Teachers of English as a Foreign Language in Institutions of Higher Education in Western China; Springer: Berlin, Germany, 2017.

4. An, F. Research on Classroom Teaching Strategies for Promoting Deep Learning. Courses Textb. Teach. Methods 2014, 11, 57-62.

5. Australian Curriculum, Assessment, and Reporting Authority. Australia Curriculum for English. Available online: https: / / docs.acara.edu.au/resources/English_Sequence_of_achievement.pdf (accessed on 10 March 2020).

6. National Reading Panel. Teaching Children to Read: An Evidence-Based Assessment of the Scientific Research Literature on Reading and Its Implications for Reading Instruction; U.S. Department of Health and Human Services, Public Health Service, National Institutes of Health, and the National Institute of Child Health and Human Development: Washington, DC, USA, 2000.

7. Jiang, X. Effects of Discourse Structure Graphic Organizers on EFL Reading Comprehension. Read. Foreign Lang. 2012, $24,84-105$. 
8. Barron, R.F. The Use of Vocabulary as an Advance Organizer. Research in Reading in the Content Areas: First Year Report; Herber, T., Vacca, S., Eds.; Syracuse University Reading and Language Arts Center: Syracuse, NY, USA, 1969; pp. 29-39.

9. Ausubel, D. In Defense of Advance Organizers: A Reply to the Critics. Rev. Educ. Res. 1978, 48, 251-257. [CrossRef]

10. Hibbard, K.M.; Wagner, E.A. Assessing and Teaching Reading Comprehension and Writing K-3; Eye on Education: New York, NY, USA, 2003; Volume 2.

11. Li, L.F. The Image of Daniel: An Ancient Graphic Organizers. J. Res. Christ. Educ. 2008, 17, 217-224. [CrossRef]

12. Yan, C. The Application of Graphic Organizer in the Reading Teaching of English Picture Books in Primary Schools. Engl. Stud. (Teach. Ed.) 2019, 12, 43-46.

13. Hawk, P.P. Using Graphic Organizers to Increase Achievement in Middle School Life Science. Sci. Educ. 1986, 70, 81-87. [CrossRef]

14. Spiegel, G.F.; Barufaldi, J.P. The Effects of a Combination of Text Structure Awareness and Graphic Post-organizers on Recall and Retention of Science Knowledge. J. Res. Sci. Teach. 1994, 31, 913-932. [CrossRef]

15. Simmons, D.C.; Griffin, C.C.; Kameenui, E.J. Effects of Teacher-Constructed Pre- and Post-Graphic Organizers Instruction on Sixth-Grade Science Students' Comprehension and Recall. J. Educ. Res. 1988, 82, 15-21. [CrossRef]

16. Armbruster, B.; Anderson, T.; Meyer, J. Improving Content Area Reading Using Instructional Graphics. Read. Res. Q. 1991, 26, 393-416. [CrossRef]

17. Josephine, T. Mindful Learning: Learner Awareness, Metacognition, and Learning Strategies; UNICA: Colombia, SC, USA, 2020.

18. Kurniaman, O.; Zufriady, Z. The Effectiveness of Teaching Materials for Graphic Organizers in Reading in Elementary School Students. J. Educ. Sci. 2019, 48, 48-62. [CrossRef]

19. Tiphaine, C.; Éric, J. Improving Students' Learning by Providing a Graphic Organizer after a Multimedia Document. Br. J. Educ. Technol. 2021, 52, 252-265.

20. Fang, Z. A Brief Discussion on the Application of Graphic Organizers, a Thinking Visualization Tool in Junior English Reading Teaching-Taking Unit 3 Traditional Skills as an Example. Engl. Teach. 2021, 21, 156-160.

21. Yin, H. Graphic organizer: An Effective Way to Promote the Integration of Reading and writing. Teach. Area 2018, $10,73-75$.

22. Weilian, H. Skillfully Use Graphics Organizers, the Visual Thinking Tool to Develop the Thinking Quality of Students-Taking Unit 10 I've had this bike for three years (Period 1) as an Example. Engl. Teach. 2020, 20, 137-153.

23. Swafford, J.; Alvermann, D. Postsecondary Research Base for Content Reading Strategies. J. Read. 1989, 33, 164-169.

24. Williams, J.P.; Nubla-Kung, A.-M.; Pollini, S.; Stafford, K.B.; Garcia, A.; Snyder, A.E. Teaching Cause-effect Text Structure Through Social Studies Content to At-risk Second Graders. J. Learn. Disabil. 2007, 40, 111-120. [CrossRef] [PubMed]

25. Ozturk, O. The Effects of Graphic Organizers on Reading Comprehension Achievement of EFL Learners. J. Educ. 2012, 2, 37-45.

26. Stull, A.T.; Mayer, R.E. Learning by Doing Versus Learning by Viewing: Three Experimental Comparisons of Learner-generated Versus Author-provided Graphic Organizers. J. Educ. Psychol. 2007, 99, 808-820. [CrossRef]

27. Hoffmann, K.F. The Impact of Graphic Organizers and Meta-Cognitive Monitoring Instruction on Expository Science Text Comprehension in Fifth Grade Students. Ph.D. Thesis, North Carolina State University, Carolina, NC, USA, 2010.

28. Minaabad, M.S. Study of the Effect of Dynamic Assessment and Graphic Organizers on EFL Learners' Reading Comprehension. J. Lang. Teach. Res. 2017, 8, 548-555. [CrossRef]

29. Ministry of Education, PRC. English Curriculum Standards for Compulsory Education, 2011th ed.; Beijing Normal University Press: Beijing, China, 2012.

30. Shapiro, E.S. Academic Skills Problems: Fourth Edition Workbook; Guilford Press: New York, NY, USA, 2011.

31. Shapiro, E.S. Academic Skills Problems: Direct Assessment and Intervention, 3rd ed.; Guilford Press: New York, NY, USA, 2004.

32. Volpe, R.J.; DiPerna, J.C.; Hintze, J.M.; Shapiro, E.S. Observing Students in Classroom Settings: A Review of Seven Coding Schemes. Sch. Psychol. Rev. 2005, 34, 454-474. [CrossRef]

33. Jiang, Y. Reflection, Change, and Reconstruction in the Context of Educational Reform and Innovation in China: Towards an Integrated Framework Centred on Reflective Teaching Practice for EFL Teachers' Professional Development; Cambridge Scholars Publishing: Newcastle upon Tyne, UK, 2012.

34. Lewis, C.S. Graphic Organizers and Text Structures. Available online: https://cpb-ca-c1.wpmucdn.com/www.rrc.ca/dist/c/31 / files/2015/08/Graphic-organizers-and-text-structure1.pdf (accessed on 11 April 2020).

35. Jiang, X.; Grabe, W. Graphic Organizers in Reading Instruction: Research Findings and Issues. Read. Foreign Lang. 2007, 19 , 34-55.

36. Bean, T.W.; Singer, H.; Sortor, J.; Frazee, C. The effects of metacognitive instruction in outlining and Graphic Organizers construction on students' comprehension in a tenth-grade world history class. J. Read. Behav. 1986, 75, 153-169. [CrossRef]

37. Robinson, D.H.; Kiewra, K.A. Visual Argument: Graphic Organizers are Superior to Outlines in Improving Learning from Text. J. Educ. Psychol. 1995, 87, 455-467. [CrossRef]

38. Lin, M. Developing EFL Learners' Morphological Awareness: Instructional Effect, Teachability of Affixes, and Learners' Perception. Int. Rev. Appl. Linguist. Lang. Teach. 2019, 57, 289-325. [CrossRef] 